\title{
CDH1 Mutation in Two Patients with Hereditary Gastric Cancer
}

\author{
Jelena Pogodina ${ }^{* * *}$, Roberts Ribenieks*, Dace Berzina ${ }^{* * *}$, Genadijs Trofimovics $^{*, * *}$, Edvins Miklasevics ${ }^{*, * *}$ \\ *Pauls Stradins Clinical University Hospital, Riga, Latvia \\ **Institute of Oncology, Riga Stradins University, Latvia
}

\section{SUMMARY}

CDH1 is currently the only gene in which mutations are known to cause hereditary diffuse gastric cancer (HDGC). Hereditary diffuse gastric cancer is defined as a syndrome of inherited predisposition to cancer with autosomal dominant inheritance pattern. Specific criteria are used to identify patients with suspected HDGC and who should be investigated for CDH1 germline mutations. Accurate screening is mandatory for unaffected carriers of $\mathrm{CDH} 1$ mutations and selected high-risk individuals could be considered for prophylactic gastrectomy.

Key words: gastric cancer, hereditary diffuse gastric cancer, $\mathrm{CDH1}$

\section{AIM OF THE DEMONSTRATION}

We report two male patients with a history of familial gastric cancer and positive $\mathrm{CDH} 1$ gene mutation.

\section{TWO CASE REPORTS}

Both patients were admitted to our hospital with diagnosis of gastric adenocarcinoma and underwent total gastrectomy. Their family history was significant for gastric cancer and patients fulfilled the hereditary diffuse gastric cancer criteria.

Patient 1 on presentation was a 54-year-old male with a family history of gastric cancer. The patient's father was diagnosed with gastric cancer and died of the disease at the age of 56 years. The father's brother was diagnosed with gastric cancer at age 51 and died two years later. The mother's brother was diagnosed and died of oesofageal cancer and mother's sister was diagnosed and died of colorectal cancer at 82 years ( Fig. 1).

The patient had epigastric pain, fatigue and weakness for approximately three month. Endoscopy revealed tumor, located in the gastric cardia. Biopsies confirmed adenocarcinoma and a total gastrectomy with Braun esophagojejunostomy was perfomed. The postoperative period was uneventful and he was discharged on the 7th day. Histopathological examination revealed poorly differentiated adenocarcinoma and 9 lymph nodes metastases, which was classified as pT3N3AM0G3Ro, stage IIIB. The patient received 45 Grays of radiotherapy and 2 courses of adjuvant chemotherapy according to ECF scheme (5- fluorouracil $1000 \mathrm{mg}$, Farmorubicin $90 \mathrm{mg}$, Cisplatin 100mg). Eleven month after total gastrectomy computed tomography revealed liver metastasis.

Patient 2 a 44-year-old man presented with abdominal pain for two month. The patient's history included two family members diagnosed with gastric carcinoma. The patient's father was diagnosed with gastric cancer at age 48 and died of the disease at the age of 49 years. A father's brother was diagnosed with gastric cancer at age
58 and died three years later. The paternal grandmother was diagnosed with kidney cancer at age 73 and died three years later ( Fig. 2). Endoscopy revealed tumor, which infiltrated the gastric wall with penetrating the serosa. Biopsies confirmed adenocarcinoma and a total gastrectomy with Braun esophagojejunostomy was perfomed. Intraoperative finding revealed a tumor extending along the lesser curvatura of the stomach from cardia to the pyloric region with the tumor invasion extending out of the stomach wall and adjacent to the great omentum. Histopathological examination revealed moderately differentiated adenocarcinoma, 8 lymph nodes metastases and great omentum metastases, witch was classified as pT4AN3AMIG2Ro, stage IV. The patient received palliative chemotherapy (Epirubicin 75 mg; Cisplatin 90 mg; Tegafur 400 mg twice a day during two week.)

DNA sequencing was performed in both patients and results showed $\mathrm{CDHI}$ gene mutation $3^{\prime} \mathrm{UTR}+54 \mathrm{C}>\mathrm{T}$ (Fig.3).

\section{DISCUSSION}

The first description of hereditary diffuse gastric cancer was in three Maori families in New Zealand and the first evidence supporting the role of $\mathrm{CDHl}$ as a major gastric cancer susceptibility gene came from genetic linkage studies in these Maori families (6).

Hereditary diffuse gastric cancer (HDGC) is an autosomal dominant genetic predisposition syndrome caused by germine mutation in the $C D H 1$ gene $(3,7)$. HDGC account for $1-3 \%$ of all gastric cancer $(7,8)$.

The $C D H 1$ gene is located on chromosome 16 and encodes E-cadherin. E-cadherin is a calcium-dependent cell-cell adhesion protein that plays a role in the maintenance of cell differentiation and the normal architecture of epithelial cells, thereby functioning as a tumor suppression protein. Mutation in the gene results in decreased gene expression and loss of function of E-cadherin. This leads to abnormal morphogenesis and 
architecture of epithelial tissue, loss of cellular polarity and contact inhibition, unregulated growth, and invasion of adjacent tissue $(5,8)$.

Between $25 \%$ and $50 \%$ of families that fit the International Gastric Cancer Linkage Consortium (IGCLC) criteria for HDGC will have autosomal dominant inherited germline $C D H 1$ mutations and about $39 \%$ of HDGC patients carry a $C D H 1$ gene mutation. The penetrance is approximately $80 \%$, so the lifetime chance of an individual with a $\mathrm{CDHl}$ mutation developing gastric cancer is high, and the risk increases with age $(4,8)$. Diffuse gastric cancer is poorly-differentiated due to defective intracellular adhesion molecules caused by mutations in E-cadherin that are common in this type of gastric cancer. These defective intracellular adhesion molecules allow individual tumor cells to grow and invade neighboring structures without distinct formations. Early detection and diagnosis of HDGC are difficult because it is mostly located submucosally, and distributed as discrete foci along the entire length of the stomach. Currently, there are no reliable screening methods for early detection. Prognosis is generally poor, because this type of cancer is often found at a later stage, is more aggressive, and more difficult to treat (1).

Due to the high risk of individuals with a $C D H 1$ gene mutation developing HDGC, the difficulty in early detection, and the relatively early age of cancer onset, genetic testing availability can greatly impact a patient's family members. Recommendations regarding mutational analysis screening were made in 1999 by the IGCLC and are for those individuals with a minimum of two cases of diffuse gastric cancer in first and/or second degree relatives, with one diagnosis before age 50 , or three or more confirmed cases with onset at any age (3). These guidelines were updated to include individuals with diffuse gastric cancer diagnosed before age 40 and individuals or family members diagnosed with HDGC and LBC or signet ring colon carcinoma before age 50 (4). The genetic testing is typically accomplished by denaturing high-performance liquid chromatography and automated DNA sequencing. It should be followed by genetic counseling to discuss the results, any risks based on the results, and options for cancer surveillance. It may be distressing for family members who test positive for a $C D H 1$ gene mutation, but they should be encouraged to share their results with family members, since genetic testing is available, and there are also IGCLC guidelines for the management of unaffected individuals. These include endoscopic examinations with screening biopsies every six months starting at age 20 (3). Annual screening (mammogram and breast magnetic resonance imaging) for LBC beginning at age 35 is advised for female $C D H 1$ mutation carriers (2). Our reported cases had family histories with multiple family members diagnosed with gastric cancer. This shows the importance of informing family members about positive mutation results, since a thorough, informative family history can potentially lead to faster testing, diagnosis, and treatment.
In conclusion, HDGC is a rare inherited cancer, with one-third to one- half of cases due to a mutation in the $\mathrm{CDHl}$ gene. Carries of the mutation have approximate $80 \%$ lifetime risk of developing HDGC. These cases highlights the importance of recognition of the HDGC syndrome and of testing for $\mathrm{CDH} 1$ germline mutations in other family members and probands' offsprings.

\section{Conflict of interest: None}

\section{REFERENCES}

1. Bevan S, Houlston RS. Genetic predisposition of gastric cancer // Q J Med 1999;92:5-10

2. Blair V, Martin I, Shaw D, Winship I, Kerr D, Arnold J, Harawira P, McLeod M, Parry S, Charlton A, Findlay M, Cox B, Humar B, More H, Guilford P. Hereditary diffuse gastric cancer: diagnosis and management // Clin Gastroenterol Hepatol 2006;4:262-275

3. Caldas C, Carneiro F, Lynch HT, Yokota J, Wiesner GL, Powell SM, Lewis FR, Huntsman DG, Pharoah PD, Jankowski JA, MacLeod P, Vogelsang H, Keller G, Park KG, Richards FM, Maher ER, Gayther SA, Oliveira C, Grehan N, Wight D, Seruca R, Roviello F, Ponder BA, Jackson CE. Familial gastric cancer: overview and guidelines for management // J Med Genet 1999:36:873-880

4. Fitzgerald RC, Hardwick R, Huntsman D, Carneiro F, Guilford P, Blair V, Chung DC, Norton J, Ragunath K, Van Krieken JH, Dwerryhouse S, Caldas C; International Gastric Cancer Linkage Consortium. Hereditary diffuse gastric cancer: updated consensus guidelines for clinical management and directions for future research // J Med Genet 2010;47:436444

5. Graziano F, Humar B, Guilford P. The role of the E-cadherin gene $(\mathrm{CDHl})$ in diffuse gastric cancer susceptibility: from the laboratory to clinical practice // Ann Oncol 2003; 14:1705-1713

6. Guilford P, Hopkins J, Harraway J, McLeod M, McLeod N, Harawira Pet al. E-cadherin germline mutations in familial gastric cancer // Nature 1998;392:402-405

7. Lynch HT, Grady W, Suriano G, Huntsman D. Gastric cancer: new genetic developments // J Surg Oncol. 2005;90:114-133

8. Oliveira C, Seruca R, Carneiro F. Genetics, pathology and clinics of familial gastric cancer // Int J Surg Pathol 2006;14:21-33 


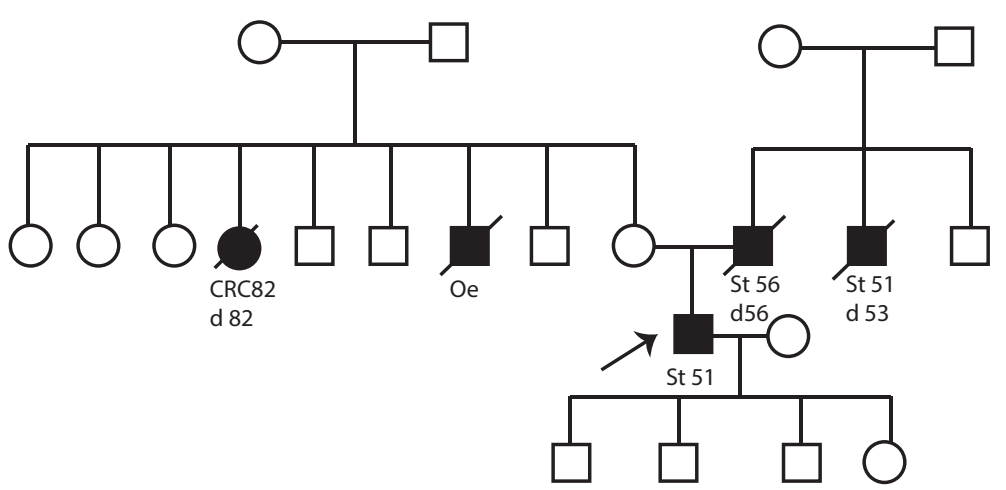

Fig. 1. Patients 1

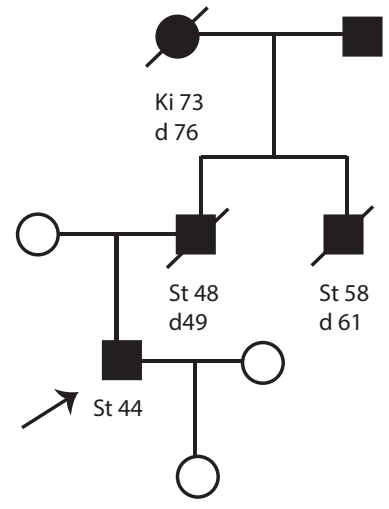

Fig. 2. Patients 2

Pedigree of families with germline CDHlmutation. Squares indicate males; circles indicate females. Solid symbols indicate the cancer patient. Symbols with a slash indicate deceased individuals. An arrow points to the proband.

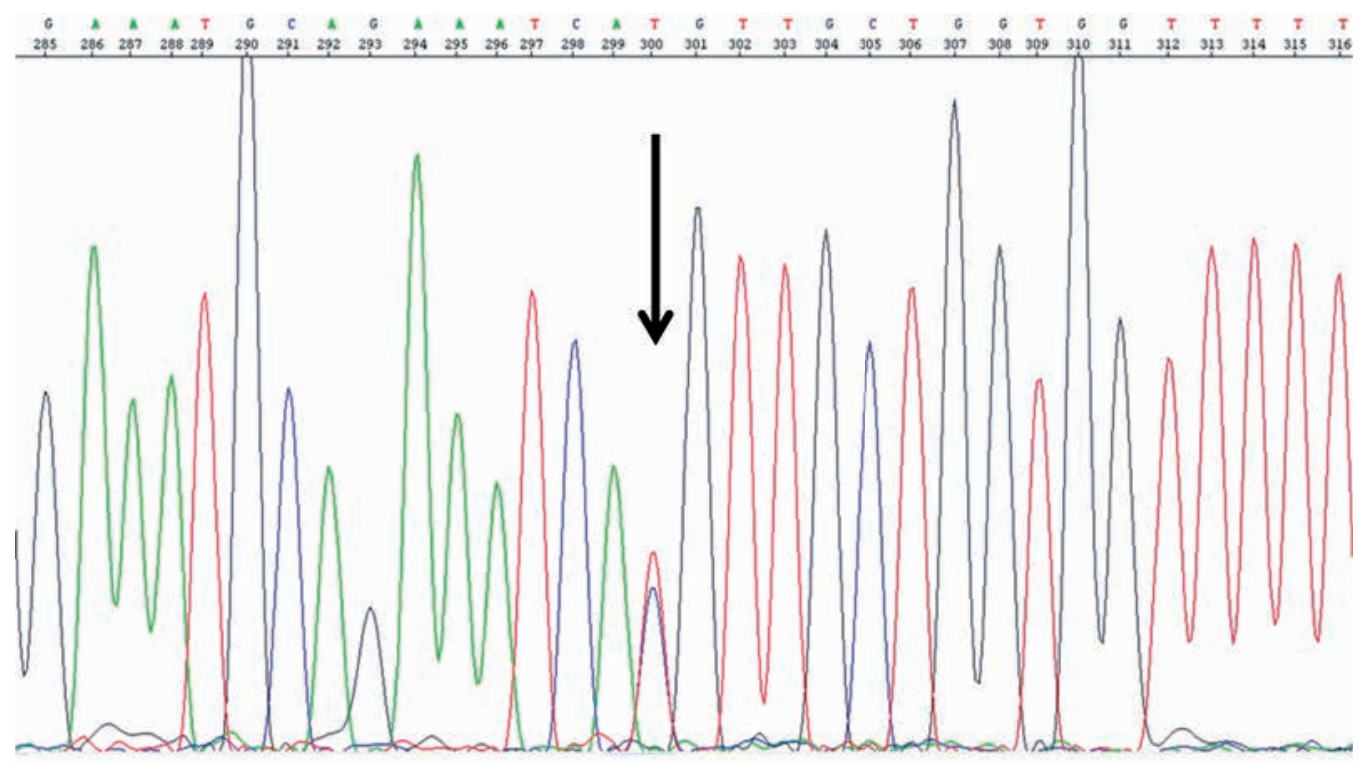

Fig. 3. CDH1 gene mutation - 3'UTR+54 C>T

\section{Address:}

Jelena Pogodina

Pauls Stradins Clinical University Hospital,

Pilsonu street 13, LV-1002,

Riga, Latvia

E-mail: raisone@inbox.lv 